$15^{\text {th }}$ International Conference on

AEROSPACE SCIENCES \& AVIATION TECHNOLOGY,

$\boldsymbol{A S A T}$ - 15 - May 28 - 30, 2013, Email: asat@mtc.edu.eg, Military Technical College, Kobry Elkobbah, Cairo, Egypt, Tel: +(202) 24025292 -24036138, Fax: +(202) 22621908

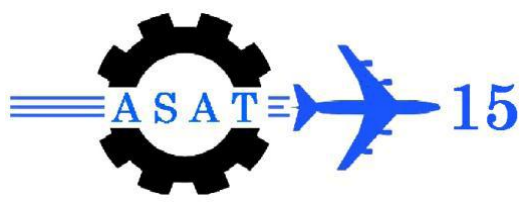

\title{
Flutter Investigation of Isotropic 3-D Wings
}

\author{
M. Haidar ${ }^{*}$, M. A. Kamel ${ }^{\dagger}$, A. M. El Shabka ${ }^{\dagger}$, H. M. Negm ${ }^{\ddagger}$
}

\begin{abstract}
The aeroelastic characteristics of wing depend upon the relationship between its aerodynamic and structural properties of the wing box. In the present work the wing box structure has been modeled using linear equivalent plate approach. The mass and stiffness matrices are calculated for a wing composed of skin, spars, and ribs based on simple polynomial functions. The static and dynamic responses to external loads are calculated for a short plate, and a wing box. The doublet point method has been used for calculating the effect of unsteady aerodynamic loads on harmonically oscillating wing in subsonic flow. Using the standard eigenvalue methodology, the solutions for the resulting complex eigenvalue problem are obtained. The V-g method has been used for determining the flutter speed of rectangle wing by calculating the natural frequencies and damping ratios. The obtained results show good agreement with published results. A parametric study has been carried out to obtain the effect of changing the thickness of skin on the flutter speed. The influence of the aspect ratio on the wing flutter speed has been shown that the flutter speed decreases when the aspect ratio increases.
\end{abstract}

Keywords: Flutter; unsteady aerodynamics; equivalent plate.

\section{Introduction}

Flutter is a dangerous aeroelastic phenomenon encountered in flexible structures subjected to aerodynamic forces. Flutter occurs as a result of interactions between aerodynamics, elastic, and inertial forces on a structure. In an aircraft, as the speed of the air increases, there may be a point at which the structural damping is insufficient to damp out the motions which are increasing due to aerodynamic energy being added to the structure. This vibration can cause structural failure, and therefore considering flutter characteristics is an essential part of designing an aircraft wing,[1].

Bakhtiari,[2], presented a linear aeroelastic analysis of a low aspect ratio swept back trapezoidal wing modeled as a cantilever plate. A Rayleigh Ritz approach has been used to transfer equations into a modal domain in order to solve equations of motion. Howard,[3] predicted of Flutter of a rectangular cantilever wing using the finite element method and the doublet lattice method in forming the aeroelastic model with Lagrange's equation. Petrolo,[4] studied An Advanced 1-D Structural Models for Flutter Analysis of Lifting Surfaces. Refined 1-D structural model were coupled with the doublet lattice method, and the g-method was used for flutter analyses. Structural models were developed in the framework of the Carrera Unified Formulation (CUF). Higher-order 1-D structural models were obtained by using Taylor-like expansions of the cross-section displacement field of the structure. The use of CUF 1-D could offer even greater advantages in the fluid-structure-interaction analysis of flexible structures with highly deformable cross-section.

Syrian Armed Forces, Syria.

$\dagger \quad$ Egyptian Armed Forces, Egypt.

* Prof. Cairo University, Egypt. 
A vast range of aerodynamic models have been utilized for solving many aeroelastic problems, from strip theories to Reynolds-averaged Navier- Stokes (RANS) theory,[4]. The doublet point method (DPM) has been proposed by Ueda and Dowell,[5], which will be utilized in this paper.

The structural component of the aeroelastic formulation adopted in this paper is based on equivalent plate modeling; Equivalent plate analysis has been used to replace the computationally expensive finite element analysis in initial design stages or in conceptual design of aircraft wing structures. In equivalent plate modeling, the model characteristics are represented by polynomials, which require only a small fraction of the input data that would be required by a corresponding finite element model. An equivalent plate analysis procedure based on the Ritz method is proposed. The aircraft wing structure is modeled with several trapezoidal segments. Stiffness and mass matrices are calculated for every segment and the total stiffness matrix $[\mathrm{K}]$ and mass matrix $[\mathrm{M}]$ of the wing can also be obtained,[6].

Aerospace structures are subjected to a wide variety of forces, which can be classified into conservative forces and nonconservative forces. Conservative systems can lose the stability of their equilibrium positions by divergence (static instability) only, whereas nonconservative systems can have two types of instability: mechanisms-divergence (static instability) and flutter (dynamic instability). These are known as aeroelastic instability behavior which is due to the highly flexible nature of the structure,[7].

In this paper, the flutter speed is investigated for rectangular wing. The wing box structure has been modeled using linear equivalent plate approach based on first order shear deformation plate theory (FSDPT). Matlab program will be built for calculating the mass and stiffness matrices of wing composed of skin, spars, and ribs, based on simple polynomial functions. Doublet point method has been used for calculating the unsteady aerodynamic loads in harmonically oscillating motion in subsonic flow. The relation between flutter speeds and the aspect ratio at the same value of the wing area has been studied. Moreover a parametric study has been conducted to get the effect of changing the thickness of skin on the flutter speed.

\section{Analytical Model}

\subsection{Aerodynamic Model}

Unsteady aerodynamics is a branch of science which studies the motion of the profile or the wing in a free stream when it changes by time, and so do the acting aerodynamic coefficients. When the changes in the motion are fast enough, the aerodynamic response of the body will have a phase lag. For fast changes in the motion, the inertia of the displaced air will contribute to the apparent mass term. If the apparent mass term is negligible, this type of analysis is called quasi-steady aerodynamics,[8]. An important problem for aeroelasticians is to evaluate the pressure distribution on a wing in oscillatory motion. Many methods have been developed for calculating the unsteady pressure distribution on a thin finite wing in subsonic flow; one of these methods is the doublet point method.

The Doublet point method is based on a concept of concentrated lift forces. The wing is divided into element surface panels on which lift distributions are represented by a single concentrated force. Since the procedure does not include any quadratures, it can be applied easily to calculate the unsteady aerodynamic loadings on complex planform wings, even when they have partial span control surfaces. The details and derivation of this method is presented in,[5]. Amplitudes of pressure distributions on oscillatory lifting surfaces and of their upwash velocity $(w)$ are related by the following integral equation:

$$
w(x, y)=\frac{1}{8 \pi} \iint_{S} \Delta P(\xi, \eta) \cdot k\left(x_{0}, y_{0}\right) d \xi d \eta
$$

where, 
$\Delta P=\frac{-P_{+}^{\prime}-P_{-}^{\prime}}{1 / 2 \rho_{\infty} \mathrm{V}^{2}} \quad$ is the pressure coefficient, $\mathrm{V}$ is flow speed,$\rho_{\infty}$ is the flow density, $P_{+}^{\prime}$ and $P_{-}^{\prime}$ are the disturbance pressure on upper and lower surfaces, $k$ is the Kernel function, and $\mathrm{S}$ is the region of the wing area, and $(\xi, \eta)$ the coordinate in $\mathrm{x}, \mathrm{y}$ direction respectively see Fig. 2.

The wing planform is divided into panel segments called element surfaces as shown in Fig. 1. The trapezoid of the element has the area $\Delta_{i}$ and width $2 \sigma_{i}$. The $(1 / 4-3 / 4)$ chord rule is adopted for element surfaces as shown in Fig. 2. The lift distribution on the surface is concentrated at the point $\left(\xi_{\mathrm{i}}, \eta_{\mathrm{i}}\right)$ on the quarter chord at the midspan of the element. This is equivalent to putting a doublet source of strength $\Delta P\left(\xi_{i}, \eta_{i}\right) . \Delta_{i}$. Thus the location $\left(\xi_{\mathrm{i}}, \eta_{\mathrm{i}}\right)$ is the doublet point of the element surface. Similarly, the upwash of the three-quarter chord point $\left(\mathrm{x}_{\mathrm{i}}, \mathrm{y}_{\mathrm{i}}\right)$ at midspan is taken as representative for the whole upwash distribution on an element surface.

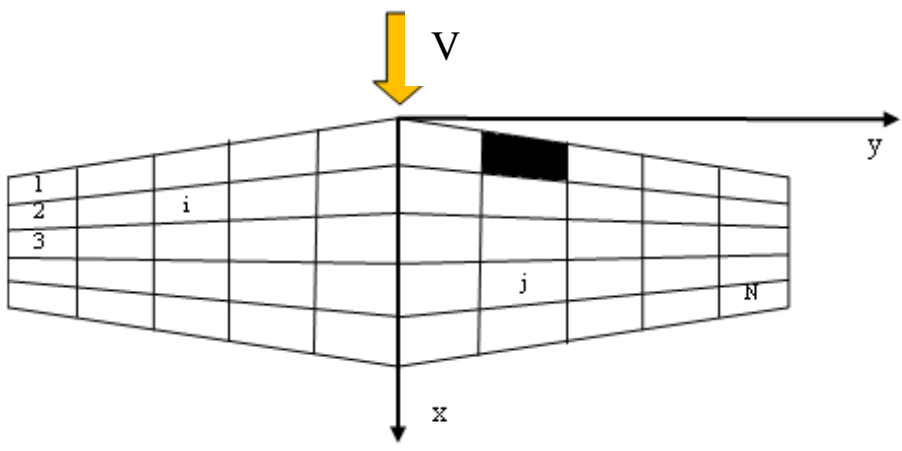

Fig. 1. Element surfaces.

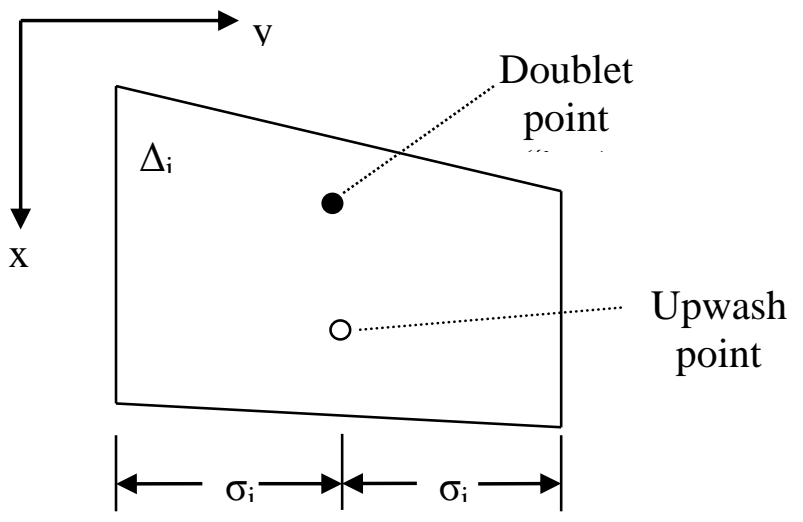

Fig. 2. The $i$ th element surface.

\subsection{Structural Model}

For a thin plate in the $\mathrm{x}-\mathrm{y}$ plane, The structure deformations $\mathrm{u}(\mathrm{x}, \mathrm{y}, \mathrm{z}, \mathrm{t}), \mathrm{v}(\mathrm{x}, \mathrm{y}, \mathrm{z}, \mathrm{t})$, and $\mathrm{w}(\mathrm{x}, \mathrm{y}, \mathrm{z}, \mathrm{t})$ in $\mathrm{x}, \mathrm{y}$ and $\mathrm{z}$ directions respectively, are given by,[9]:

$$
\begin{aligned}
& \mathrm{u}(\mathrm{x}, \mathrm{y}, \mathrm{z}, \mathrm{t})=\mathrm{u}_{0}(\mathrm{x}, \mathrm{y}, \mathrm{t})-\mathrm{z} \psi_{\mathrm{x}}(\mathrm{x}, \mathrm{y}, \mathrm{t}) \\
& \mathrm{v}(\mathrm{x}, \mathrm{y}, \mathrm{z}, \mathrm{t})=\mathrm{v}_{0}(\mathrm{x}, \mathrm{y}, \mathrm{t})-\mathrm{z} \psi_{\mathrm{y}}(\mathrm{x}, \mathrm{y}, \mathrm{t}) \\
& \mathrm{w}(\mathrm{x}, \mathrm{y}, \mathrm{z}, \mathrm{t})=\mathrm{w}_{0}(\mathrm{x}, \mathrm{y}, \mathrm{t})
\end{aligned}
$$

These expressions include five different unknown functions: 
$\mathrm{u}_{0}(\mathrm{x}, \mathrm{y}, \mathrm{t}), \mathrm{v}_{0}(\mathrm{x}, \mathrm{y}, \mathrm{t}), \mathrm{w}_{0}(\mathrm{x}, \mathrm{y}, \mathrm{t}), \psi_{\mathrm{x}}(\mathrm{x}, \mathrm{y}, \mathrm{t})$, and $\psi_{\mathrm{y}}(\mathrm{x}, \mathrm{y}, \mathrm{t})$ for the deformation field of the plate. The Ritz approximation method is used in displacement formulation and the five $\mathrm{x}, \mathrm{y}$ dependent deformation functions are approximated by:

$$
\begin{aligned}
& \mathrm{u}_{0}(\mathrm{x}, \mathrm{y}, \mathrm{t})=\left\{\mathrm{a}_{1}(\mathrm{x}, \mathrm{y})\right\}^{\mathrm{T}} \cdot\left\{\mathrm{q}_{1}(\mathrm{t})\right\} \\
& \mathrm{v}_{0}(\mathrm{x}, \mathrm{y}, \mathrm{t})=\left\{\mathrm{a}_{2}(\mathrm{x}, \mathrm{y})\right\}^{\mathrm{T}} \cdot\left\{\mathrm{q}_{2}(\mathrm{t})\right\} \\
& \Phi_{\mathrm{x}}(\mathrm{x}, \mathrm{y}, \mathrm{t})=\left\{\mathrm{a}_{3}(\mathrm{x}, \mathrm{y})\right\}^{\mathrm{T}} \cdot\left\{\mathrm{q}_{3}(\mathrm{t})\right\} \\
& \Phi_{\mathrm{y}}(\mathrm{x}, \mathrm{y}, \mathrm{t})=\left\{\mathrm{a}_{4}(\mathrm{x}, \mathrm{y})\right\}^{\mathrm{T}} \cdot\left\{\mathrm{q}_{4}(\mathrm{t})\right\} \\
& \mathrm{w}_{0}(\mathrm{x}, \mathrm{y}, \mathrm{t})=\left\{\mathrm{a}_{5}(\mathrm{x}, \mathrm{y})\right\}^{\mathrm{T}} \cdot\left\{\mathrm{q}_{5}(\mathrm{t})\right\}
\end{aligned}
$$

where $a_{1}(x, y)$ to $a_{5}(x, y)$ are column vectors of polynomial terms of the form $x^{m} y^{n}$.

The column vectors $\left\{\mathrm{q}_{1}\right\},\left\{\mathrm{q}_{2}\right\},\left\{\mathrm{q}_{3}\right\},\left\{\mathrm{q}_{4}\right\}$, and $\left\{\mathrm{q}_{5}\right\}$ contain the polynomial coefficients which are the generalized displacements in the Ritz formulation.

The wing structure is made of a cover skin and an internal array of spar and rib as shown in Fig. 3. The depth of a wing segment $h(\mathrm{x}, \mathrm{y})$, as well as thicknesses of skin $t(\mathrm{x}, \mathrm{y})$, spar web $t_{s w}(\mathrm{y})$, and rib web $t_{r b}(\mathrm{x})$ are all defined mathematically using simple polynomials:

$$
\begin{gathered}
h(x, y)=\sum_{g=1}^{x_{t h}} H(g) \cdot x^{m h(g)} \cdot y^{n h(g)} \\
t(x, y)=\sum_{k=1}^{N_{t t}} T(k) \cdot x^{m t(k)} \cdot y^{n t(k)} \\
t_{s w}(y)=\sum_{k=1}^{N_{t s w}} T_{s w}(k) \cdot y^{n t s w(k)} \\
t_{r b}(x)=\sum_{k=1}^{N_{t r b}} T_{r b}(k) \cdot x^{n t r b(k)}
\end{gathered}
$$

With the coefficients $H(g), T(k), T_{s w}(k)$ and $T_{r b}(k)$ and the set of powers chosen.

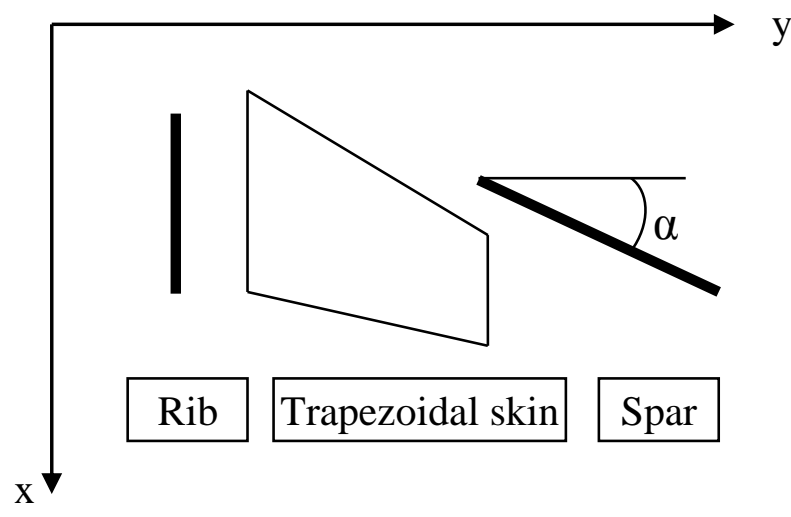

Fig. 3. Planform geometry of wing trapezoids, spars, and ribs. 
The total energy $E_{\text {tot }}$ associated with the wing model is

$$
\mathrm{E}_{\mathrm{tot}}=\mathrm{U}+\mathrm{W}-\mathrm{T}
$$

where $\mathrm{U}$ is the strain energy stored in the structure through deformation, $\mathrm{W}$ is the work of the applied loads moving through the corresponding structural deflections, and $\mathrm{T}$ is the kinetic energy associated with the mass of the structure. All the equations used for calculating the stiffness and mass matrices of a isotropic plate wing are presented in,[9].

The kinetic and potential energies are derived for wing-box members then added together noting that; skins carry in-plane stresses ( $\mathrm{x}-\mathrm{y}$ plane), spar and rib caps carry axial loads; spar and rib webs carry transverse shear as well as axial loads,[10]. The general equations for the strain and kinetic energies respectively are:

$$
\begin{aligned}
U & =\frac{1}{2} \int_{y} \int_{x}\{\varepsilon\}^{T}[Q]\{\varepsilon\} d x d y \\
T & =\frac{1}{2} \int_{y} \int_{x} \rho \cdot\left[\begin{array}{lll}
\dot{\mathrm{u}} & \dot{\mathrm{v}} & \dot{\mathrm{w}}
\end{array}\right] \cdot\left[\begin{array}{lll}
\dot{\mathrm{u}} & \dot{\mathrm{v}} & \dot{\mathrm{w}}
\end{array}\right]^{T} d x d y
\end{aligned}
$$

where $[\mathrm{Q}]$ is the constitutive matrix, $\{\varepsilon\}$ is the strain vector, and $\rho$ is the material density.

Table 1. shows the adaptation of the above formulas for kinetic and strain energies for each

\begin{tabular}{|c|c|c|}
\hline Component & Potential energy & Kinetic energy \\
\hline Skin & $\frac{1}{2} \iint_{y} t_{x}\{\varepsilon\}^{T}[Q]\{\varepsilon\} d x d y$ & $\frac{1}{2} \rho \iint_{y} t_{x}\left(\dot{\mathrm{u}}^{2}+\dot{\mathrm{v}}^{2}+\dot{\mathrm{w}}^{2}\right) d x d y$ \\
\hline Spar-Cap & $\frac{1}{2} E_{0} \int A \varepsilon_{l l}^{2} d l$ & $\frac{1}{2} \rho \int_{y} \int_{x} A\left(\dot{\mathrm{u}}^{2}+\dot{\mathrm{v}}^{2}+\dot{\mathrm{w}}^{2}\right) d l$ \\
\hline Spar-Web & $\frac{1}{2} \iint t_{s w}\left\{\begin{array}{l}\varepsilon_{l l} \\
\varepsilon_{z l}\end{array}\right\}^{T}[\bar{Q}]\left[\begin{array}{l}\varepsilon_{l l} \\
\varepsilon_{z l}\end{array}\right\} d z d l$ & $\frac{1}{2} \rho \iint_{y} t_{x w}\left(\dot{\mathrm{u}}^{2}+\dot{\mathrm{v}}^{2}+\dot{\mathrm{w}}^{2}\right) d z d l$ \\
\hline Rib-Cap & $\frac{1}{2} E_{0} \int A \varepsilon_{x x}^{2} d x$ & $\frac{1}{2} \rho \iint_{y} A\left(\dot{\mathrm{u}}^{2}+\dot{\mathrm{v}}^{2}+\dot{\mathrm{w}}^{2}\right) d x$ \\
\hline Rib-Web & $\left.\frac{1}{2} \iint t_{r w}\left\{\begin{array}{l}\varepsilon_{x x} \\
\varepsilon_{z x}\end{array}\right\}^{T}[\bar{Q}]\right]\left\{\begin{array}{l}\varepsilon_{x x} \\
\varepsilon_{z x}\end{array}\right\} d z d x$ & $\frac{1}{2} \rho \iint_{y} t_{r w}\left(\dot{\mathrm{u}}^{2}+\dot{\mathrm{v}}^{2}+\dot{\mathrm{w}}^{2}\right) d z d x$ \\
\hline
\end{tabular}
member of the wing depending on its contribution in carrying the loads.

Table 1 Energy-expression forms for wing-box members,[1]].

The vectors and matrices in Table 1 are defined as,[11]: 


$$
\begin{aligned}
& \{\varepsilon\}=\left\{\begin{array}{l}
\varepsilon_{x x} \\
\varepsilon_{y y} \\
\varepsilon_{x y}
\end{array}\right\} \\
& {[Q]=\frac{E_{0}}{1-v^{2}}\left[\begin{array}{ccc}
1 & v & 0 \\
v & 1 & 0 \\
0 & 0 & 1-v
\end{array}\right]} \\
& {[\bar{Q}]=\frac{E_{0}}{1-v^{2}}\left[\begin{array}{cc}
1 & 0 \\
0 & 1-v
\end{array}\right]} \\
& \left\{\varepsilon_{l l}\right\}=\left\{\begin{array}{lll}
\sin ^{2} \alpha & \cos ^{2} \alpha & 2 \sin \alpha \cos \alpha
\end{array}\right\}\left\{\begin{array}{l}
\varepsilon_{x x} \\
\varepsilon_{y y} \\
\varepsilon_{x y}
\end{array}\right\} \\
& \left\{\varepsilon_{z l}\right\}=\left\{\begin{array}{ll}
\sin \alpha & \cos \alpha
\end{array}\right\}\left\{\begin{array}{l}
\varepsilon_{x z} \\
\varepsilon_{y z}
\end{array}\right\}
\end{aligned}
$$

where $E_{0}$ is the young's modulus, $[\bar{Q}]$ is the constitutive matrix, $A$ is the area of cabs, and $v$ is Poisson's ratio.

For distributed loads $P_{x}(x, y, t)$ in $x$ direction, $P_{y}(x, y, t)$ in $y$ direction, and $P_{z}(x, y, t)$ in $z$ direction; the external work is defined by:

$$
\{P\}=\iint_{x y}\left[\begin{array}{c}
P_{x} \cdot\left\{a_{1}\right\} \\
P_{y} \cdot\left\{a_{2}\right\} \\
z P_{x} \cdot\left\{a_{3}\right\} \\
z P_{y} \cdot\left\{a_{4}\right\} \\
P_{z} \cdot\left\{a_{5}\right\}-z P_{x} \cdot\left\{a_{5, x}\right\}-z P_{y} \cdot\left\{a_{5, y}\right\}
\end{array}\right] d x . d y
$$

The loads $P_{x}, P_{y}, P_{z}$ can be constant, time-dependent, or functions of the generalized displacements $\{q\}$.

The equation of motion -in case of dynamic load without damping- will take the form:

$$
[M]\{\ddot{q}\}+[K]\{q\}=\{P\}
$$

where: $[M]$ and $[K]$ are the mass and stiffness matrices respectively. For a static loading condition Eq. (12) becomes

$$
[K]\{q\}=\{P\}
$$

\subsection{Aeroelastic Model}

An aeroelastic analysis of the wing in the subsonic regime requires formulation of the governing equations of motion for flexible wing. A general solution of the governing equations of motion gives the eigenvalue problem, [12]:

$$
\left|[K]-\omega^{2}\left([M]+\left[Q^{*}\right]\right)\right|=0
$$

where: $Q^{*}$ is the unsteady aerodynamic load. 
Solving the eigenvalue problem gives

$$
\begin{array}{ll}
\omega^{2}=\operatorname{Re}\left(\omega^{2}\right)+\operatorname{Im}\left(\omega^{2}\right) \\
\omega=\sqrt{\operatorname{Re}\left(\omega^{2}\right)} & \text { Flutter frequency } \\
g=\frac{\operatorname{Im}\left(\omega^{2}\right)}{\operatorname{Re}\left(\omega^{2}\right)} & \text { Damping coefficient }
\end{array}
$$

\section{Results and Discussion}

Matlab program has been built for calculating the stiffness matrix $[K]$, mass matrix $[M]$, and Kernel function $\mathrm{k}$ for isotropic plate and wing. Then the vertical tip deflection due to static and dynamic load has been calculated. The flutter speed has been predicted due to unsteady aerodynamic load $Q^{*}$.

\subsection{Validation of Equivalent Plate Results}

\subsubsection{Short cantilevered plate}

Using the standard eigenvalue methodology, the static and dynamic response is obtained for a short cantilevered plate made of isotropic material with $E=90 \mathrm{Gpa}, v=0.3$, and density of $2700 \mathrm{~kg} / \mathrm{m}^{3}$. The plate is cantilevered and subjected to a uniform vertical pressure over its area. The plate chord, length, and thickness are $30 \mathrm{~cm}, 10 \mathrm{~cm}$, and $1 \mathrm{~mm}$ respectively. Figure 4 shows the normalized vertical tip deflection of the plate under static load. The nondimensional load parameter is represented by $P_{0} a^{4} / E h^{4}$, where $P_{0}$ is the uniform pressure magnitude, $a$ is the length, $E$ is Young's modulus, and $h$ is the thickness. The vertical tip displacement of the plate is normalized by the plate length. The equivalent plate results in the Fig. 4. for static responses using Ritz coefficients in each series expressions are shown a good agreement compared with those of Livne's,[13].

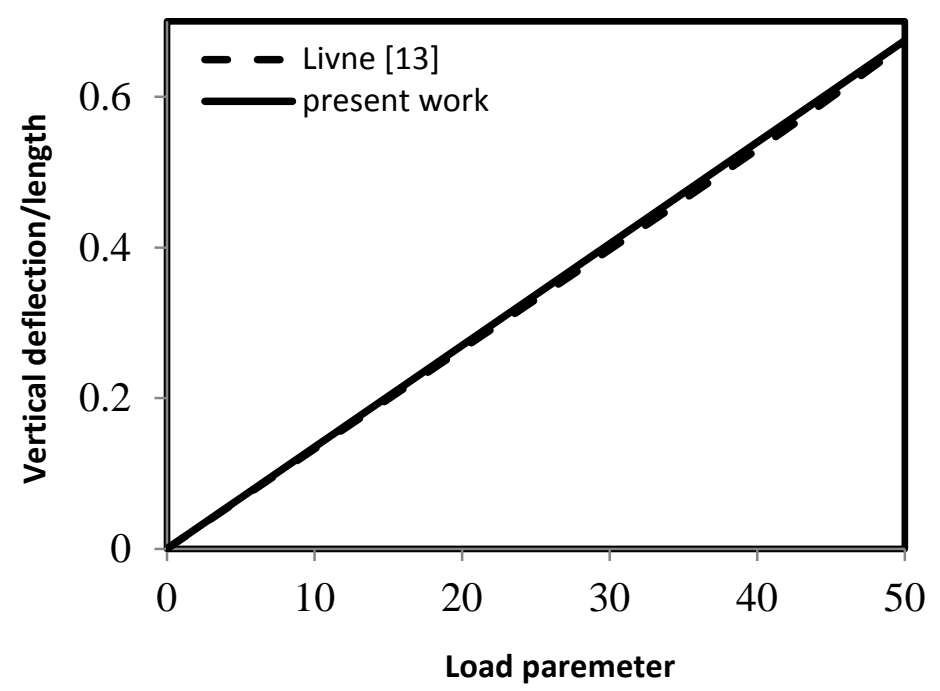

Fig. 4. Normalized tip vertical deflection, short cantilevered plate.

For a uniform pressure step load of $15.0 \mathrm{kPa}$ (load parameter $=16.7$ ) the time history of the normalized vertical tip displacement is predicted. Fig. 5. shows the vertical tip deflection time response calculated by Livne theory and the equivalent plate method using Ritz coefficients in the series expansions. Good agreement between the results is obtained for dynamic responses. 


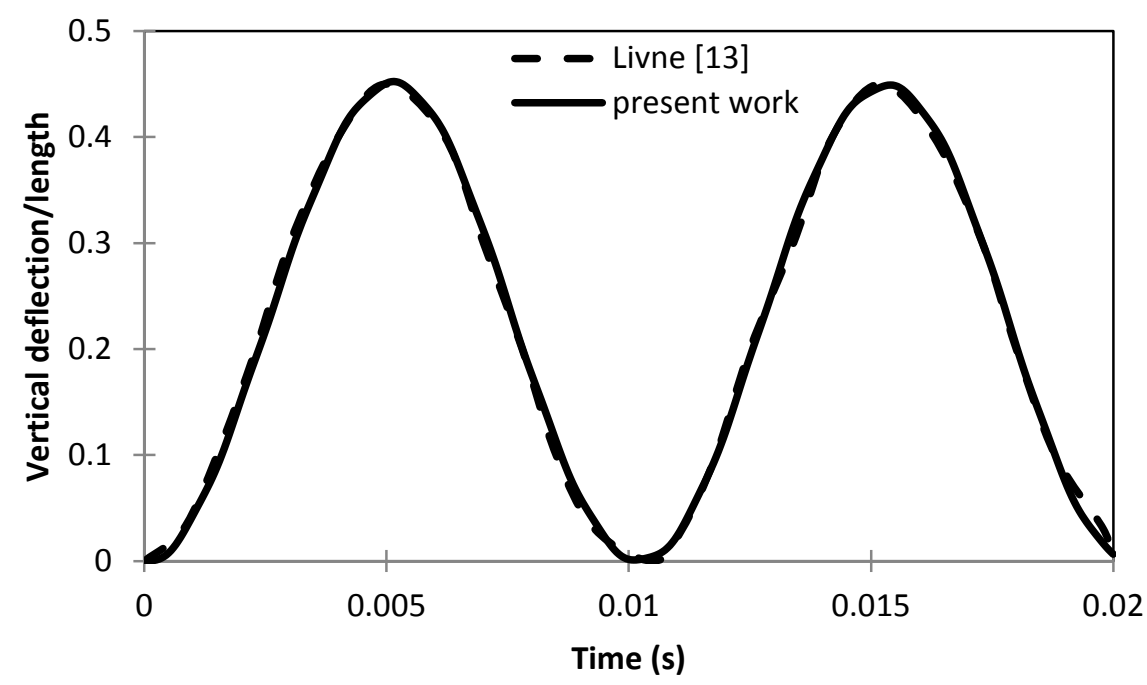

Fig. 5. Vertical tip deflection time response to $15-\mathrm{kPa}$ uniform pressure step input, short cantilevered plate.

\subsubsection{Wing-box}

The wing-box tested here is $10 \mathrm{~m}$ long, has $2 \mathrm{~m}$ chord, and is $0.2 \mathrm{~m}$ deep,[13]. Overall, 2 skins, 10 ribs, 2 spar webs, and 10 caps are included in the equivalent plate model of the wing box. An isotropic material is used for the entire structure. Its Young modulus $E=68.95 \mathrm{GPa}$, $v=0.3$ and density $\rho=2709.7 \mathrm{~kg} / \mathrm{m}^{3}$. All of the skin thicknesses are set equal to $8.128 \times 10^{-4} \mathrm{~m}$, and all of the spar- and rib-web thicknesses are $1.295 \times 10^{-3} \mathrm{~m}$. The spar cap areas are set to be $2.3935 \times 10^{-4} \mathrm{~m}^{2}$ each, and the stiffener areas are $39.36 \times 10^{-6} \mathrm{~m}^{2}$.

The wing box is cantilevered and subjected to six concentrated forces as shown in Fig. 6. One in-plane force is applied (its direction is parallel to wing plane) to each of the front and rear spar caps (four in-plane forces in total). In addition, two vertical forces are applied at the tip of the wing box, one in the plane of the web of the front spar and one in the plane of the web of the rear spar.

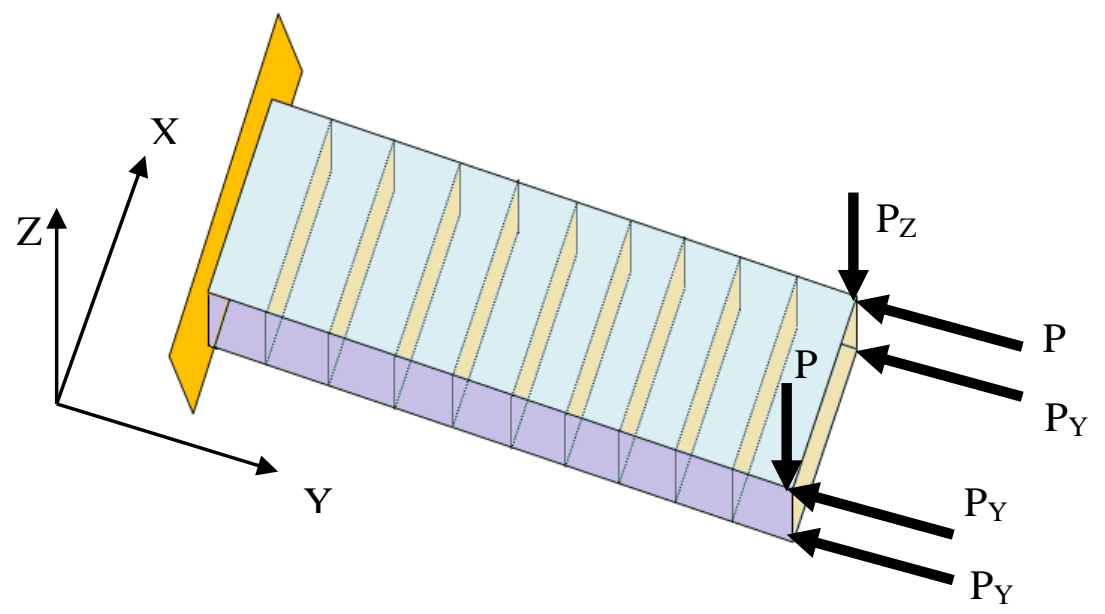

Fig. 6. Wing box geometry and applied load.

Figure 7 shows the vertical tip central deflection due to the above static applied loads compared with work of Livne,[13]. 


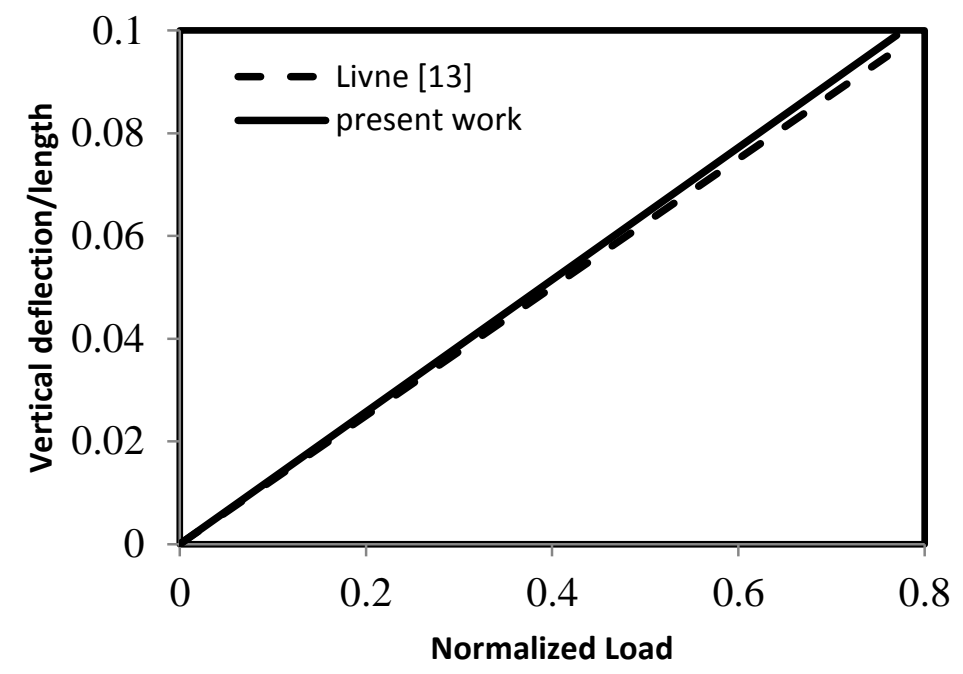

Fig. 7. Wing box maximum static central vertical deflection due to symmetric in-plane and vertical applied loads.

For dynamic testing, the loads (in-plane and vertical) are first increased from zero to $1000 \mathrm{~N}$ using a ramp that lasts $0.05 \mathrm{~s}$., after which the loads are kept constant. The dynamic response is shown in Fig. 8.

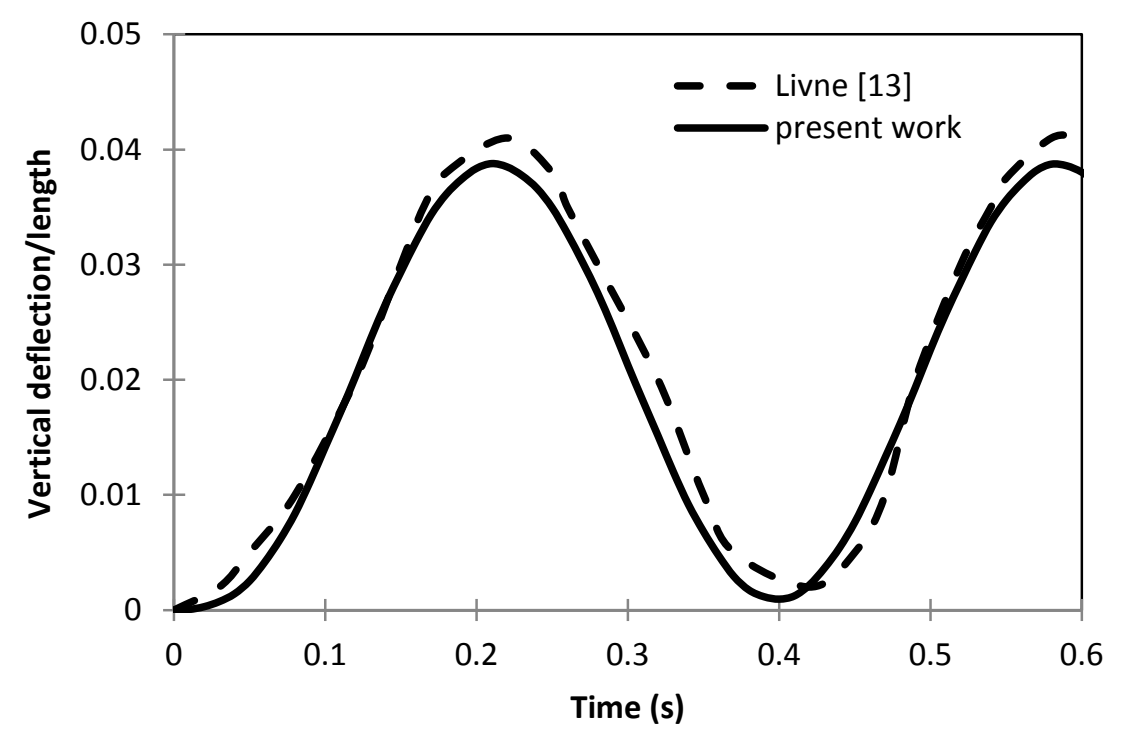

Fig. 8. Wing box tip central dynamic response due to symmetric in-plane and vertical applied load $=1000 \mathrm{~N}$ ramp from 0 in $0.05 \mathrm{~s}$.

The results show good agreement between the prediction of the present model and that of Ref.[13] in both the static and dynamic responses.

\subsection{Prediction of Flutter Speed and Parametric Study}

For the wing discussed in reference,[10], the stiffness and mass matrices were calculated using the equivalent plate method, and the unsteady aerodynamic load was calculated using the doublet point method. By solving the eigenvalue problem, the flutter speed was obtained at altitude of $3048 \mathrm{~m}$. Show the change of damping coefficient with the speed of wing, the 
intersection of third mode of vibration of wing with the $\mathrm{x}$ - axis defines the flutter speed $\mathrm{V}_{\mathrm{F}}=175[\mathrm{~m} / \mathrm{s}]$ which is shows good agreement with reference,[10] as $\mathrm{V}_{\mathrm{F}}=180[\mathrm{~m} / \mathrm{s}]$.

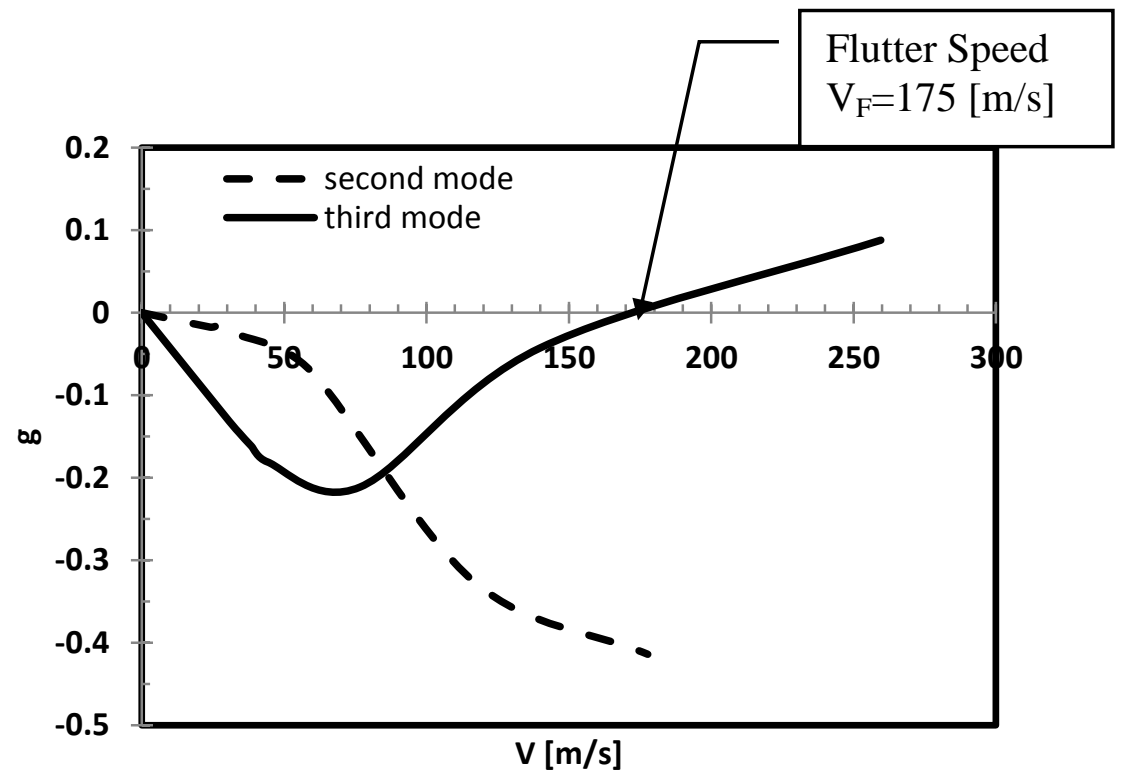

Fig. 9. V-g curve for wing.

The number of elements (Nx, Ny) used to calculate the unsteady aerodynamic load has an effect on the flutter speed. Fig. 10. shows the variation of the flutter speed when the number of elements in the $\mathrm{x}$ direction $(\mathrm{Nx})$ is changed at a fixed number of elements in the y direction $(\mathrm{Ny}=5)$, and the same thing due to $\mathrm{Ny}$. In case of $(\mathrm{Nx}=\mathrm{Ny})$, the flutter speed approximately remains constant, so the flutter speed has obtained in this paper is calculated in case $\mathrm{Nx}=\mathrm{Ny}$.

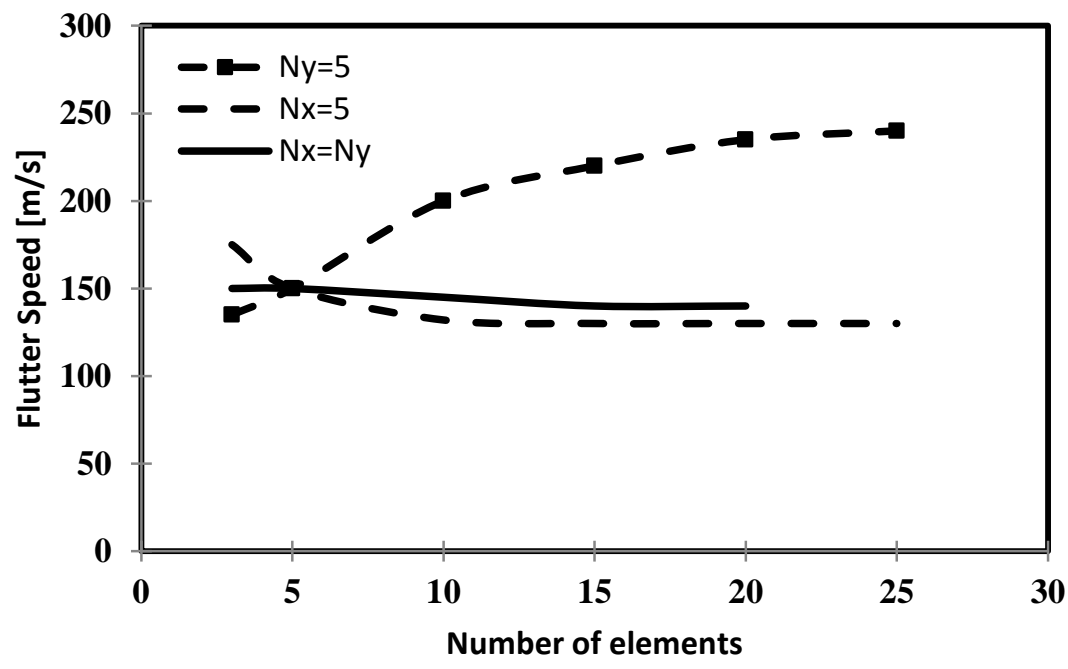

Fig. 10. Relation between flutter speed and the number of aerodynamic elements.

The wing box of Fig. 11. is discussed in section 3-2, The variation of the flutter speed with the skin thickness for two materials: aluminum and steel, has been studied. 


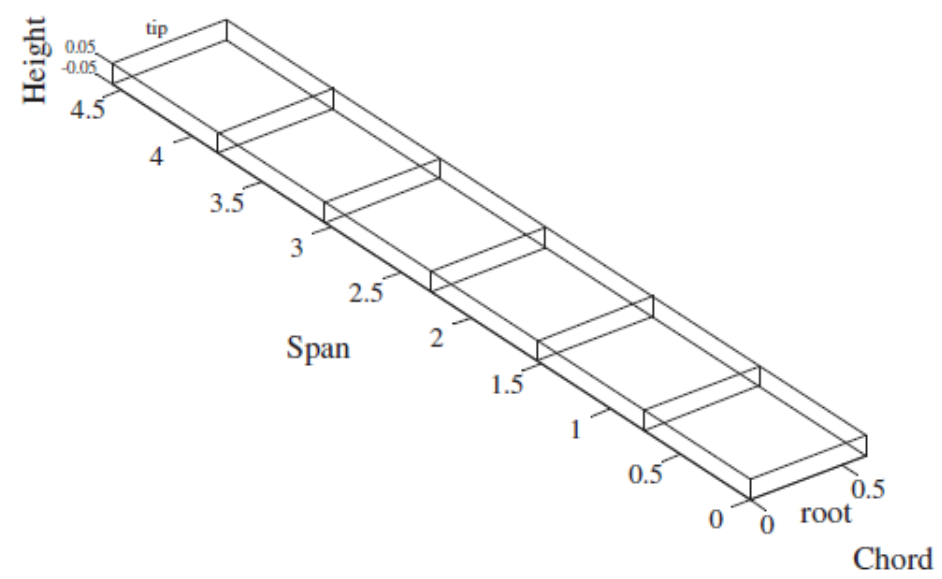

Fig. 11. Wing box model,[10].

Figure 12 shows that the flutter speed for the wing box increases when the thickness of skin increases. Also, the flutter speed for the skin made of steel is greater than that for skin made of aluminum.

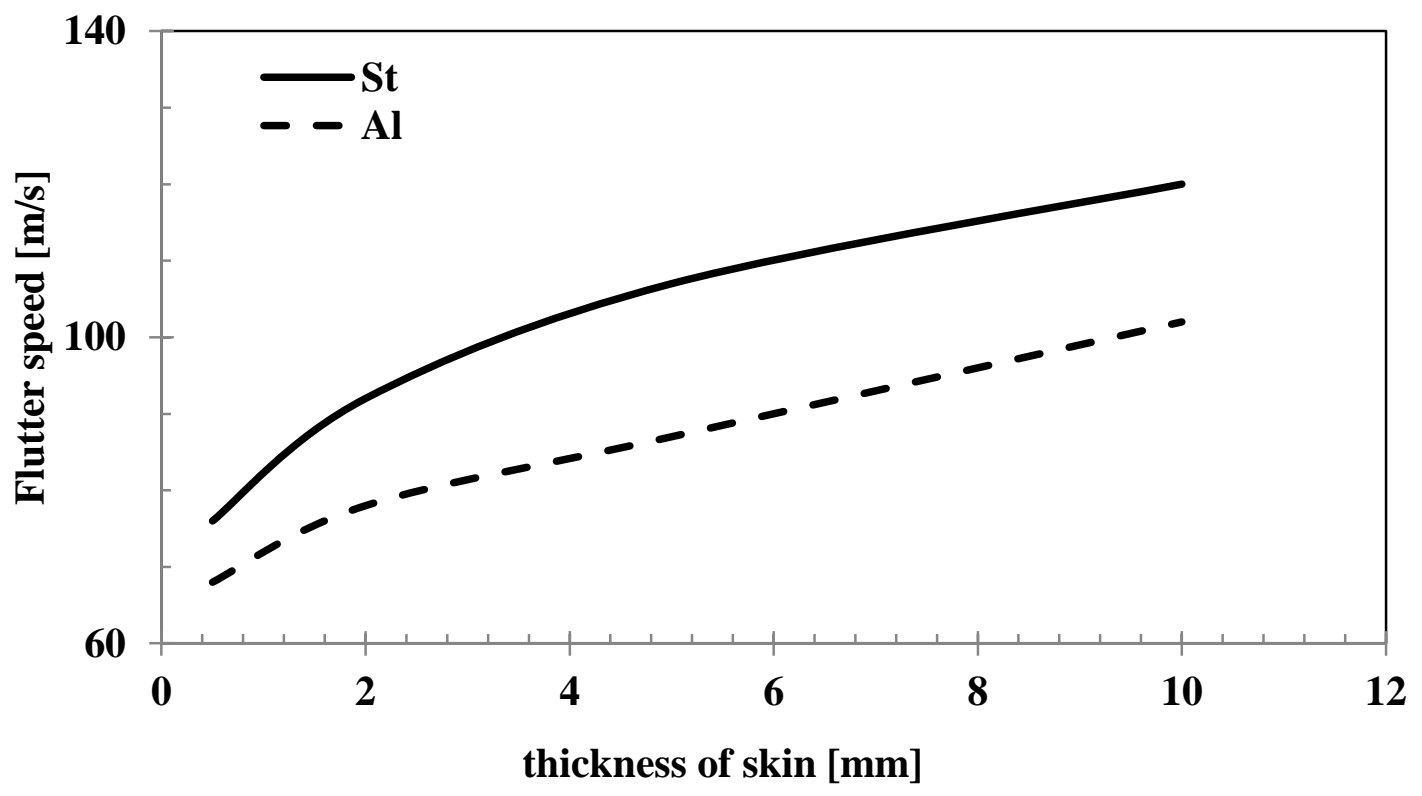

Fig. 12. Relation between flutter speed and the thickness of skin.

For a fixed area of wing $\left(\sim 5.8 \mathrm{~m}^{2}\right)$, Fig. 13 shows the change of flutter speed with the aspect ratio. Because decreasing of stiffness of wing when the aspect ratio increases, the flutter speed decreases when the aspect ratio increases. 


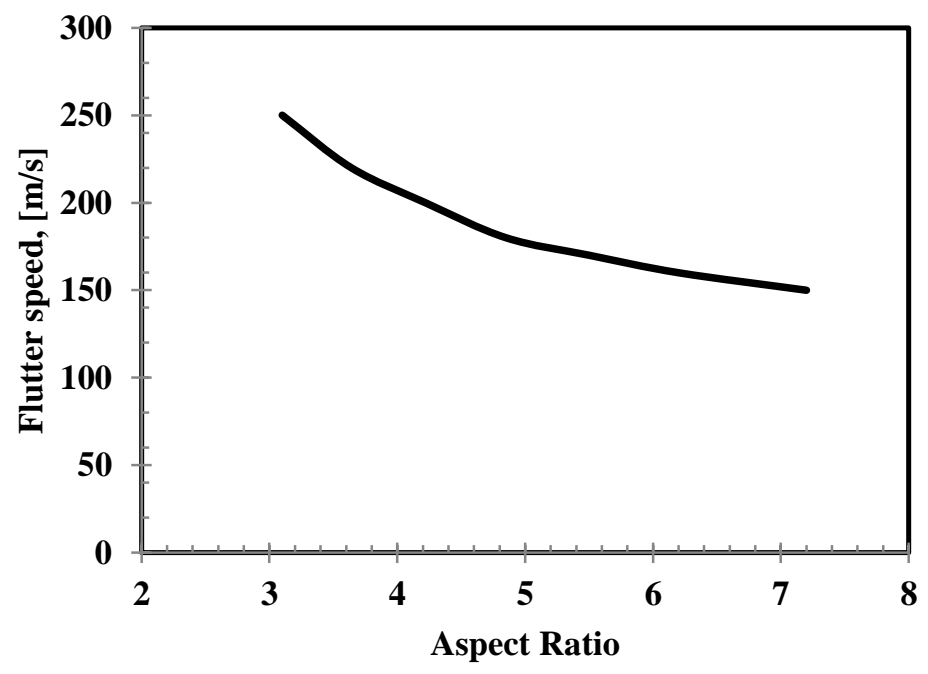

Fig. 13 Relation between flutter speed and the aspect ratio.

\section{Conclusion}

The aeroelastic behavior of isotropic wing has been studied in subsonic flow by solving the complex eigenvalue problem that indicates the relation between the aerodynamic properties of wing and structure properties of the wing box.

The results of static vertical deflection and dynamic response for cantilevered plate show good agreement compared with ref. [13]. The static tip deflection and dynamic response for wing box composed of skin, spars, and ribs have been calculated, the result shown a good agreement compared with ref. [13].

The flutter speed for rectangular wing has been determined by calculating the natural frequencies and damping ratios. The obtained results show good agreement with ref. [10].

The influence of the aspect ratio on the wing flutter speed has been shown that the flutter speed decreases when the aspect ratio increases.

The variation of the flutter speed with the thickness of skin has been shown that the flutter speed increases when the thickness of skin increases in case of aluminum and steel materials. In addition, the flutter speed in case of steel is greater than for aluminum.

\section{References}

[1] Dave Cowan Chad Hebert, Attar Peter J, and Carol D. Weiseman. (1996). Aerodynamic Flutter.

[2] S. Shokrollahi, "Flutter Analysis of a Low Aspect Ratio Swept," JAST, vol. Vol.3, No.2, pp. 61-66, 2006.

[3] Howard J. Conyers, "Aeroelastic Studies of a Rectangular Wing with a Hole: Correlation of Theory and Experiment," Duke University, 2007.

[4] Marco Petrolo, "Advanced 1D Structural Models for Flutter Analysis of Lifting Surfaces," IJASS, pp. 199-209, 2012.

[5] T. Ueda, "A New Solution Method for Lifting Surfaces in Subsonic Flow," AIAA Journal, vol. VOL. 20, NO. 3, pp. 348 - 355, 1982.

[6] T. Krishnamurthy, "Equivalent Plate Analysis of Aircraft Wing with Discrete Source Damage," AIAA Journal, vol. VA 23681, 2005. 
[7] P. K. Datta and S. Biswas, "Aeroelastic Behaviour of Aerospace Structural Elements with Follower Force: A Review," Int'1 J. of Aeronautical \& Space Sci., pp. 134-148, 2011.

[8] Ulgen Gulcat, Fundementals Of Modern Unsteady Aerodynamics. Berlin Heidelberg: Springer-Verlag 2010.

[9] Eli Livne, "Equivalent Plate Structural Modeling for Wing Shape Optimization Including transverse Shear," AIAA Journal, vol. Vol. 32, No.6, 1994.

[10] Ramadan Otiefy and Hani M. Negm, "Wing box transonic-flutter suppression using piezoelectric self-sensing diagonal-link actuators," International Journal of Solids and Structures, vol. 48, pp. 31-43, 2011.

[11] Ramadan Otiefy and Hani M. Negm, "Wing Box Flutter Suppression using piezoelectric Controllers," Master, Faculty of Engineering, Cairo university, Cairo, 2006.

[12] Steven Hollowell and Jhon Dugundji, "Aeroelastic Flutter and Divergence of Stiffness Coupled Graphite/Epoxy Cantilevered Plate," J. Aircraft, vol. Vol. 21, NO.1, 1984.

[13] Eli Livne, "Nonlinear Equivalent Plate Modeling of Wing -Box Structures," J. Aircraft, vol. Vol 36 No.5, pp. 851-864, 1999. 